University of Nebraska - Lincoln

DigitalCommons@University of Nebraska - Lincoln

M. Eugene Rudd Publications

Research Papers in Physics and Astronomy

1968

Excitation of Auto-Ionizing Levels in Neon by lon Impact

A. K. Edwards

University of Nebraska - Lincoln

M. Eugene Rudd

University of Nebraska - Lincoln, erudd@unl.edu

Follow this and additional works at: https://digitalcommons.unl.edu/physicsrudd

Part of the Physics Commons

Edwards, A. K. and Rudd, M. Eugene, "Excitation of Auto-lonizing Levels in Neon by lon Impact" (1968). M. Eugene Rudd Publications. 58.

https://digitalcommons.unl.edu/physicsrudd/58

This Article is brought to you for free and open access by the Research Papers in Physics and Astronomy at DigitalCommons@University of Nebraska - Lincoln. It has been accepted for inclusion in M. Eugene Rudd Publications by an authorized administrator of DigitalCommons@University of Nebraska - Lincoln. 


\title{
Excitation of Auto-Ionizing Levels in Neon by Ion Impact
}

\author{
A. K. Edwards * and M. E. Rudd \\ Behlen Laboratory of Physics, University of Nebraska, Lincoln, Nebraska 68508
}

Received 31 January 1968

Auto-ionizing states of neutral and singly ionized neon were produced by bombarding neon gas with $\mathrm{H}+, \mathrm{He}^{+}$, and $\mathrm{Ne}+$ ions in the 150-250-keV energy range. Sixty lines in the electron spectrum were found, of which 43 have been classified into 13 Rydberg series. Ten of these series were previously unreported. Auger electrons from one- and two-vacancy states are also reported. Relative intensities of all transitions are listed.

Published in Physical Review 170, 140 - 144 (1968)

(C)1968 The American Physical Society. Used by permission.

URL: http://link.aps.org/doi/10.1103/PhysRev.170.140

DOI: 10.1103/PhysRev.170.140

* Present address: Department of Physics, University of Washington, Seattle, Wash. 


\title{
Excitation of Auto-Ionizing Levels in Neon by Ion Impact*†
}

\author{
A. K. EDwards $\ddagger$ AND M. E. RUDD \\ Behlen Laboratory of Physics, University of Nebraska, Lincoln, Nebraska 68508
}

(Received 31 January 1968)

\begin{abstract}
Auto-ionizing states of neutral and singly ionized neon were produced by bombarding neon gas with $\mathrm{H}^{+}$, $\mathrm{He}^{+}$, and $\mathrm{Ne}^{+}$ions in the 150-250-keV energy range. Sixty lines in the electron spectrum were found, of which 43 have been classified into 13 Rydberg series. Ten of these series were previously unreported. Auger electrons from one- and two-vacancy states are also reported. Relative intensities of all transitions are listed.
\end{abstract}

\section{INTRODUCTION}

$\mathrm{E}$ XCITED states of neon with energies above the first ionization potential have been studied only in relatively recent times. Simpson et al. ${ }^{1}$ excited several levels by electron impact and identified some of the states observed in their energy-loss spectrum. Rudd and Lang ${ }^{2}$ observed the electron-energy spectrum from ion impact on neon and found a prominent line spectrum superimposed on a background continuum. The lines were identified with certain transitions from innershell excited states to neighboring continua. A similar method was used by Barker and Berry ${ }^{3}$ with much lower ion-beam energies. Körber and Mehlhorn ${ }^{4}$ used a relatively high-energy electron beam to excite innershell vacancy states which they observe as peaks in the energy spectrum of emitted electrons. A new and extensive list of highly excited states in neon has recently been published by Codling et al., ${ }^{5}$ who observe these states as asymmetric resonances in the uv absorption

* This work was supported by the National Science Foundation. + Based in part on a thesis presented by A. K. E. in partial fulfillment of the requirements for the degree of Doctor of Philosophy.

† Present address: Department of Physics, University of Washington, Seattle, Wash.

1 J. Arol Simpson, S. R. Mielczarek, and J. Cooper, J. Opt. Soc. Am. 54. 269 (1964).

${ }_{2}$ M. E. Rudd and D. V. Lang, in Proceedings of the Fourth International Conference on the Physics of Electronic and Atomic Collisions, Quebec, 1965, edited by L. Kerwin and W. Fite (Science Bookcrafters, Hastings-on-Hudson, N. Y., 1965), p. 153.

3 R. B. Barker and H. W. Berry, Phys. Rev. 151, 14 (1966).

${ }^{4}$ H. Körber and W. Mehlhorn, Z. Physik 191, 217 (1966).

${ }^{5}$ K. Codling, R. P. Madden, and D. L. Ederer, Phys. Rev. 155,26 (1967). spectrum of neon gas. Their observations were limited to states which could be reached from the ground state by optical transitions.

The present experiment, following the method of Rudd and Lang, ${ }^{2}$ allows the observation of transitions which are optically forbidden. With better electronenergy resolution and greater intensities than the earlier experiment, ${ }^{2}$ it was possible to detect many more states. As a result of this additional data it was necessary to reassign some lines to different series than previously given. In addition we report a number of auto-ionizing states of singly ionized neon not previously observed and some inner-shell vacancy states which have been observed by another method. ${ }^{4} \mathrm{~A}$ comparison is made of the relative effectiveness of electrons and protons in producing single- and double-vacancy states.

\section{EXPERIMENTAL APPARATUS AND PROCEDURE}

A magnetically analyzed ion beam entered a differentially pumped collision chamber containing the neon target gas at pressures of 2-7 $\mu$. Electrons emitted by the target gas were observed at $160^{\circ}$ from the beam direction, energy analyzed by a parallel-plate electrostatic analyzer, and detected by a 14-stage Dumont electron multiplier. The counting rate normalized to incident beam current was plotted on an $X-Y$ recorder against electron energy. The apparatus is described in more detail elsewhere. ${ }^{6}$

\footnotetext{
${ }^{6}$ M. E. Rudd, Rev. Sci. Instr. 37, 971 (1966).
} 
The energy of the 11-40 eV portion of the spectrum was calibrated using the transition from the $2 s 2 p^{6} 3 p\left({ }^{1} P\right)$ state, the energy of which is given by Codling et al. ${ }^{5}$

The observed transition energies were assigned to Rydberg series given by

$$
E=E_{\infty}-13.60 Z^{2} /(n-\mu)^{2} \text {, }
$$

where $E$ is the energy of the ejected electron, $E_{\infty}$ is the energy of the series limit, $Z$ is the charge of the finalstate configuration, $n$ is the principal quantum number, and $\mu$ is the quantum defect. The values of $E_{\infty}$ were calculated from energy levels tabulated by Moore. ${ }^{7}$ The line intensities in the electron spectrum were also used in identifying the series. In nearly every case these were greatest for $n=3$ and decreased with increasing $n$. The actual energy of the state configuration is found by adding the ejected energy of the electrons (the measured peak energy) to the energy of the neon ion formed after auto-ionization. These latter energies were obtained from Ref. 7.

For the series formed by inner-shell excitations the quantum defect of neon was compared to the quantum defect of the sodium-atom configuration which resembled the excited neon state. The differences in the quantum defects of neon and sodium for the $2 s 2 p^{6} n l$ and the $2 s 2 p^{5}\left({ }^{1} P\right) n l$ series was less than 0.1 . The same comparison cannot be made for the auto-ionizing states formed from two-electron excitations since these have two electrons in the outer shell.

The selection rules for an auto-ionizing transition from an initial excited state to a final continuum state are $\Delta L=\Delta S=\Delta J=\Delta \pi=0$. Codling et al. ${ }^{5}$ noted that $L S$ coupling held for almost all of the auto-ionizing states of neon which they observed, so the restrictions on $L$ and $S$ were used. The ground state of Ne I is a singlet state, so excited states of $\mathrm{Ne}$ I produced by $\mathrm{H}^{+}$ impact should also be singlet states since triplet states can only be formed by an electron-exchange process. Likewise, the excited states of $\mathrm{Ne}$ II produced by $\mathrm{H}^{+}$ impact will be doublets. ${ }^{8}$

\section{EXPERIMENTAL RESULTS}

Figure 1 is a composite drawing of the electron spectra produced by $150-\mathrm{keV} \mathrm{H}^{+}, 150-\mathrm{keV} \mathrm{He}^{+}$, and $250-\mathrm{keV} \mathrm{Ne}^{+}$impacts. It was found that the $\mathrm{He}^{+}$beam formed strong ${ }^{3} S$ and ${ }^{3} P$ series of Ne $\mathrm{I}$; in particular, the $2 s 2 p^{6} n s\left({ }^{3} S\right)$ and $2 s 2 p^{6} n p\left({ }^{3} P\right)$ series. The singlet states of these series were formed by the $\mathrm{H}^{+}$beam. An attempt was made to separate the singlet and triplet components of the $n=3$ members by increasing the resolution. This was done by decelerating the electrons to $2 \mathrm{eV}$ before analyzing. The results are shown in Fig. 2. Only a very small peak at $22.07 \mathrm{eV}$ is present on the side of the $3 s$ line while the $3 p$ line has been split into three components,

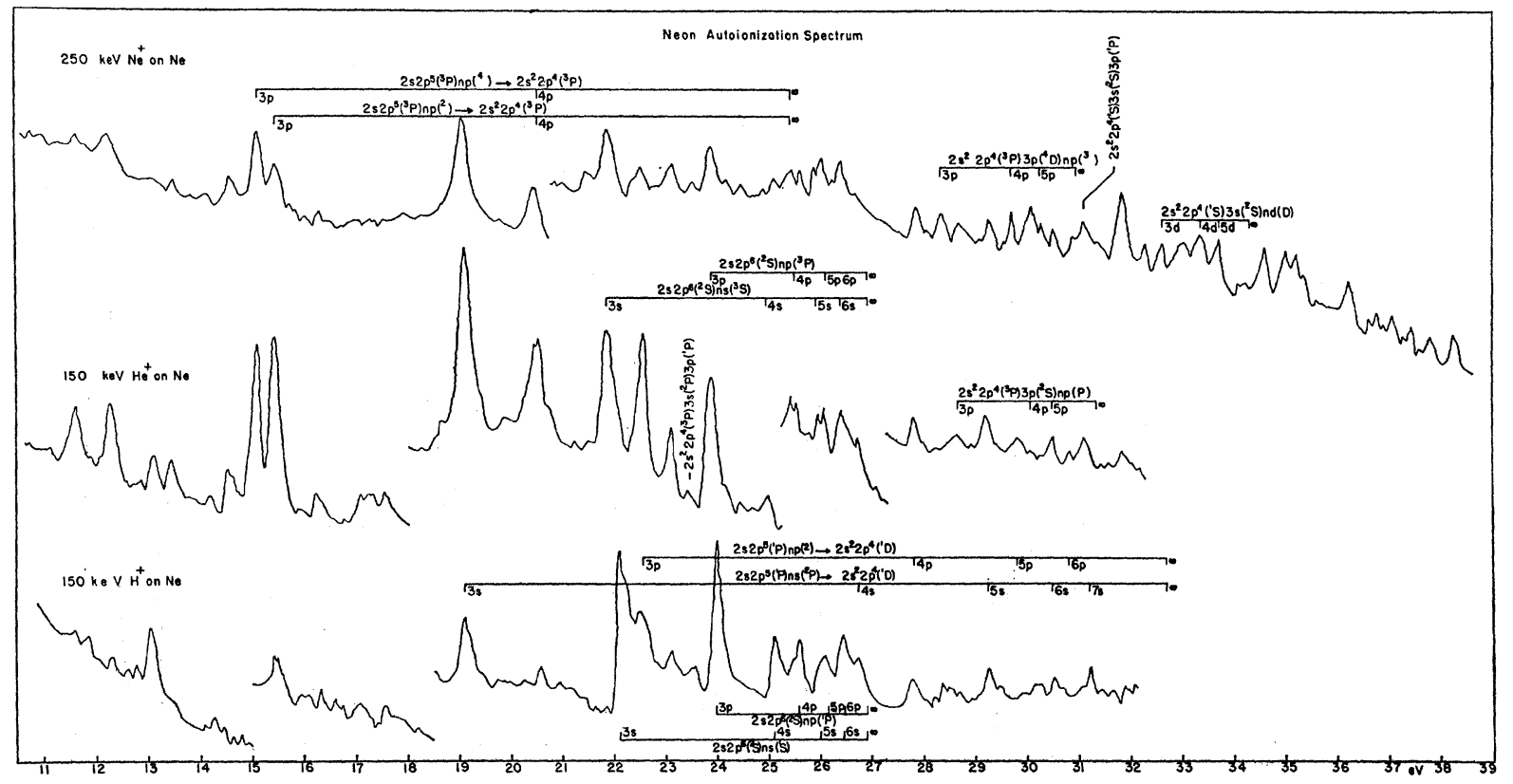

Fig. 1. Electron-energy spectra from neon gas bombarded by $250-\mathrm{keV} \mathrm{Ne}^{+}, 150-\mathrm{keV} \mathrm{He}^{+}$, and $150-\mathrm{keV} \mathrm{H}^{+}$. The peaks are due to auto-ionization electrons from highly excited states of neutral and singly ionized neon atoms. Identified transitions are indicated. Note different relative intensities obtained with different projectiles. 7 C. Moore, Atomic Energy Levels, Natl. Bur. Std. (U. S.) Circular No. 467 (U. S. Government Printing Office, Washington, D. C.,
1949), Vol. I.

${ }^{8}$ For a discussion of selection rules for excitation by ion impact and for auto-ionization, see M. E. Rudd and Kenneth Smith, Phys. Rev. (to be published). 


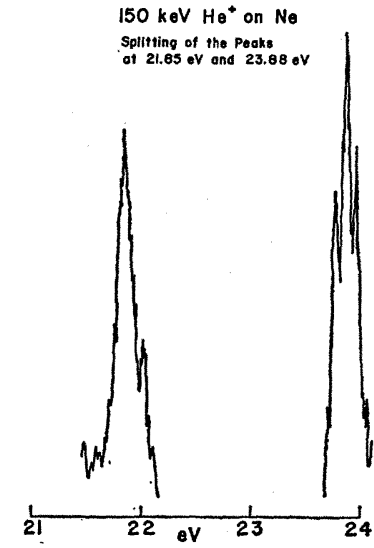

Fig. 2. Higher-resolution spectra of the 22- and 24-eV regions showing the separation of the singlet and triplet components produced by $150-\mathrm{keV}$ $\mathrm{He}^{+}$impacts on neon gas. with $0.1-\mathrm{eV}$ spacing. Noting that the $2 p^{5}\left({ }^{2} P_{3 / 2,1 / 2}\right) \mathrm{com}-$ ponents of the ground state are $0.1 \mathrm{eV}$ apart (21.56 and $21.66 \mathrm{eV}$ ), the three peaks could be explained as follows. The first peak is due to the transition from the ${ }^{3} P$ to the ${ }^{2} P_{1 / 2}$ final state, the second peak is due to two transitions, ${ }^{3} P$ to ${ }^{2} P_{3 / 2}$ and ${ }^{1} P$ to ${ }^{2} P_{1 / 2}$, while the third peak is the ${ }^{1} P$ to ${ }^{2} P_{3 / 2}$ transition.

The transitions in the $10-18-\mathrm{eV}$ range were identified on the basis of (a) their quantum defects, and (b) whether they appeared using the $\mathrm{H}^{+}$beam or only with the beams of $\mathrm{He}^{+}$and $\mathrm{Ne}^{+}$which can exchange an electron with the target. The quantum defects are approxi- mately unity for $n s$ series and 0.7 for $n p$ series. The positions and intensities of all observed lines are listed in Table I along with the quantum defects and identifications were known. Of the 13 Rydberg series listed, 3 have been observed optically. ${ }^{5}$

In addition to excitations involving the $L$ shell of neon, $K$-shell vacancies and also simultaneous $K$ - and $L$-shell vacancies were produced. These were observed in the energy spectrum of Auger electrons as peaks in the $700-800-\mathrm{eV}$ region. It was found that higher beamparticle velocities produced stronger lines in this region so an energy near the upper limit of our accelerator (300 keV) was selected. The spectrum is shown in Fig. 3 with the strongest lines identified. Some of the weaker lines were more distinct in other trials under different conditions.

The energy scale in this region was calibrated with an electron gun with an accurately known cathode voltage. No correction was made for the work function of the cathode material. However, by extrapolating to zero pressure the energy scale of the neon spectrum was corrected for the source potential due to space charge formed around the beam. The energies determined this way are believed to be accurate to $0.5 \mathrm{eV}$. All of the measured transition energies are within $0.2 \mathrm{eV}$ of those measured by Körber and Mehlhorn ${ }^{4}$ and therefore are not listed here. In Table II we list the relative intensities of our lines and compare with the electron-impact data.

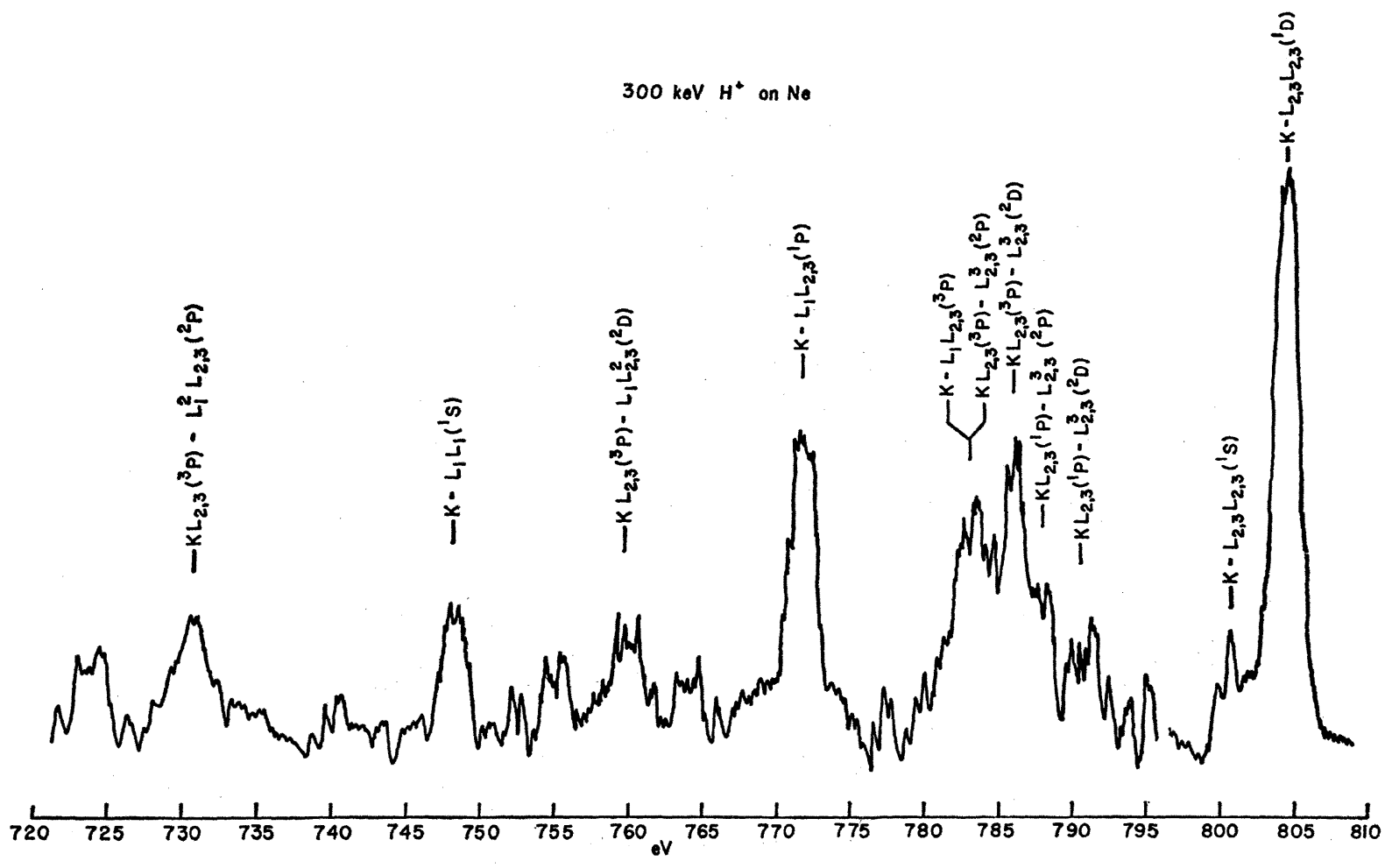

FIG. 3. Electron-energy spectrum from neon produced by $300-\mathrm{keVH}^{+}$. The peaks are due to Auger electrons from $K$-shell vacancy states and $K$-and $L$-shell vacancy states. Note:Above $795.5_{m} \mathrm{eV}_{\mathrm{n}}$ the vertical scale has been reduced by a factor of 2 . 
TABLE I. Auto-ionizing transitions observed from $\mathrm{H}^{+}, \mathrm{He}^{+}$, and $\mathrm{Ne}^{+}$impacts.

\begin{tabular}{|c|c|c|c|c|c|c|c|}
\hline \multirow{2}{*}{$\begin{array}{l}\text { Electron } \\
\text { energy } \\
(\mathrm{eV})\end{array}$} & \multirow{2}{*}{$\begin{array}{l}\text { State } \\
\text { energy } \\
(\mathrm{eV})\end{array}$} & \multirow[b]{2}{*}{$\mu^{\mathrm{a}}$} & \multirow[b]{2}{*}{ Auto-ionizing state } & \multicolumn{3}{|c|}{ Relative intensity } & \multirow{2}{*}{$\begin{array}{l}\text { Final } \\
\text { state }\end{array}$} \\
\hline & & & & $\mathrm{H}^{+}$ & $\mathrm{He}^{+}$ & $\mathrm{Ne}^{+}$ & \\
\hline 11.63 & 74.27 & 1.01 & $2 s 2 p^{5}\left({ }^{3} P\right) 3 s\left({ }^{4} P\right)$ & & 20 & 2 & $2 p^{4}\left({ }^{3} P\right)$ \\
\hline 12.27 & 78.11 & 0.66 & $2 s 2 p^{5}\left({ }^{3} P\right) 3 p\left({ }^{2} D\right)$ & 0.05 & 20 & 2 & $2 p^{4}\left({ }^{1} D\right)$ \\
\hline 13.10 & 75.74 & 0.90 & $2 s 2 p^{5}\left({ }^{3} P\right) 3 s\left({ }^{2} P\right)$ & 0.2 & 10 & & $2 p^{4}\left({ }^{3} P\right)$ \\
\hline 13.45 & 79.29 & 0.51 & $2 s 2 p^{5}\left({ }^{3} P\right) 3 p\left({ }^{2} S\right)$ & & 8 & 0.5 & $2 p^{4}\left({ }^{1} D\right)$ \\
\hline 14.20 & & & & & 3 & & \\
\hline 14.55 & 77.19 & 0.76 & $2 s 2 p^{5}\left({ }^{3} P\right) 3 p\left({ }^{4} D\right)$ & & 9 & 0.8 & $2 p^{4}\left({ }^{3} P\right)$ \\
\hline 15.10 & 77.74 & 0.70 & $2 s 2 p^{5}\left({ }^{3} P\right) 3 p\left({ }^{4} P\right)$ & & 40 & 2 & $2 p^{4}\left({ }^{3} P\right)$ \\
\hline 15.45 & 78.09 & 0.66 & $2 s 2 p^{5}\left({ }^{3} P\right) 3 p\left({ }^{2} D\right)$ & 0.1 & 50 & 2 & $2 p^{4}\left({ }^{3} P\right)$ \\
\hline 16.27 & 78.91 & 0.56 & $2 s 2 p^{5}\left({ }^{3} P\right) 3 p\left({ }^{2} P\right)$ & 0.05 & 10 & 0.5 & $2 p^{4}\left({ }^{3} P\right)$ \\
\hline 17.10 & & & & & 10 & & \\
\hline 17.28 & & & & & 20 & & \\
\hline 17.56 & & & & 0.05 & 10 & & \\
\hline 19.10 & 84.94 & 1.00 & $2 s 2 p^{5}\left({ }^{1} P\right) 3 s\left({ }^{2} P\right)$ & 0.5 & 80 & 5 & $2 p^{4}\left({ }^{1} D\right)$ \\
\hline 20.50 & 83.14 & 0.67 & $2 s 2 p^{5}\left({ }^{3} P\right) 4 p\left({ }^{4} P\right)$ or $\left({ }^{2} D\right)$ & 0.1 & 60 & 2 & $2 p^{4}\left({ }^{3} P\right)$ \\
\hline 21.85 & 43.41 & 1.36 & $2 s 2 p^{6}\left({ }^{2} S\right) 3 s\left({ }^{2} S\right)$ & & 50 & 3 & $2 p^{5}\left({ }^{2} P\right)$ \\
\hline 22.12 & 43.68 & 1.32 & $2 s 2 p^{6}\left({ }^{2} S\right) 3 s\left({ }^{1} S\right)$ & 0.7 & & & $2 p^{5}\left({ }^{2} P\right)$ \\
\hline 22.42 & 85.06 & 0.72 & $2 s 2 p^{5}\left({ }^{3} P\right) 5 p\left({ }^{4} P\right)$ or $\left({ }^{2} D\right)$ & & 20 & & $2 p^{4}\left({ }^{3} P\right)$ \\
\hline 22.55 & 88.39 & 0.69 & $2 s 2 p^{5}\left({ }^{1} P\right) 3 p\left({ }^{2} ?\right)$ & 0.5 & 30 & 1 & $2 p^{4}\left({ }^{1} D\right)$ \\
\hline 23.09 & & & & 0.3 & 30 & 1 & \\
\hline 23.46 & 45.02 & 1.23 & $2 p^{4}\left({ }^{3} P\right) 3 s\left({ }^{2} P\right) 3 p\left({ }^{1} P\right)$ & 0.2 & 10 & 0.4 & $2 p^{5}\left({ }^{2} P\right)$ \\
\hline 23.88 & 45.44 & 0.88 & $2 s 2 p^{6}\left({ }^{2} S\right) 3 p\left({ }^{3} P\right)$ & & 50 & 2 & $2 p^{5}\left({ }^{2} P\right)$ \\
\hline 23.98 & 45.54 & 0.85 & $2 s 2 p^{6}\left({ }^{2} S\right) 3 p\left({ }^{1} P\right)$ & 0.5 & & & $2 p^{5}\left({ }^{2} P\right)$ \\
\hline 24.17 & & & & & 20 & 0.4 & \\
\hline 24.45 & & & & & 10 & 0.2 & \\
\hline 24.94 & 46.50 & 1.37 & $2 s 2 p^{6}\left({ }^{2} S\right) 4 s\left({ }^{3} S\right)$ & & 20 & & $2 p^{5}\left({ }^{2} P\right)$ \\
\hline 25.10 & 46.66 & 1.26 & $2 s 2 p^{6}\left({ }^{2} S\right) 4 s\left({ }^{1} S\right)$ & 0.2 & & 0.5 & $2 p^{5}\left({ }^{2} P\right)$ \\
\hline 25.40 & & & & & 20 & & \\
\hline 25.50 & 47.06 & 0.89 & $2 s 2 p^{6}\left({ }^{2} S\right) 4 p\left({ }^{3} P\right)$ & & 20 & & $2 p^{5}\left({ }^{2} P\right)$ \\
\hline 25.58 & 47.14 & 0.80 & $2 s 2 p^{6}\left({ }^{2} S\right) 4 p\left({ }^{1} P\right)$ & 0.2 & & 0.3 & $2 p^{5}\left({ }^{2} P\right)$ \\
\hline 25.92 & 47.48 & 1.29 & $2 s 2 p^{6}\left({ }^{2} S\right) 5 s\left({ }^{3} S\right)$ & & 9 & & $2 p^{5}\left({ }^{2} P\right)$ \\
\hline 26.00 & 47.56 & 1.13 & $2 s 2 p^{6}\left({ }^{2} S\right) 5 s\left({ }^{1} S\right)$ & 0.2 & & 0.3 & $2 p^{5}\left({ }^{2} P\right)$ \\
\hline 26.10 & 47.66 & 0.90 & $2 s 2 p^{6}\left({ }^{2} S\right) 5 p\left({ }^{3} P\right)$ & & 9 & & $2 p^{5}\left({ }^{2} P\right)$ \\
\hline 26.15 & 47.71 & 0.77 & $2 s 2 p^{6}\left({ }^{2} S\right) 5 p\left({ }^{1} P\right)$ & 0.2 & & & $2 p^{5}\left({ }^{2} P\right)$ \\
\hline 26.38 & 47.94 & 0.93 & $2 s 2 p^{6}\left({ }^{2} S\right) 6 s\left({ }^{3} S\right)$ or $6 p\left({ }^{3} P\right)$ & & 20 & 0.2 & $2 p^{5}\left({ }^{2} P\right)$ \\
\hline 26.45 & 48.01 & 0.56 & $2 s 2 p^{6}\left({ }^{2} S\right) 6 s\left({ }^{1} S\right)$ or $6 p\left({ }^{1} P\right)$ & 0.3 & & & $2 p^{5}\left({ }^{2} P\right)$ \\
\hline 26.74 & 92.58 & 0.98 & $2 s 2 p^{5}\left({ }^{1} P\right) 4 s\left({ }^{2} P\right)$ & 0.3 & 10 & & $2 p^{4}\left({ }^{1} D\right)$ \\
\hline 27.82 & 93.66 & 0.65 & $2 s 2 p^{5}\left({ }^{1} P\right) 4 p\left({ }^{2} ?\right)$ & 0.1 & 10 & 0.3 & $2 p^{4}\left({ }^{1} D\right)$ \\
\hline 28.32 & 49.88 & 0.72 & $2 p^{4}\left({ }^{3} P\right) 3 p\left({ }^{4} D\right) 3 p\left({ }^{3} ?\right)$ & & & 0.3 & $2 p^{5}(2 P)$ \\
\hline 28.65 & 50.21 & 0.75 & $2 p^{4}\left({ }^{3} P\right) 3 p\left({ }^{2} S\right) 3 p\left({ }^{?} P\right)$ & & 10 & 0.2 & $2 p^{5}\left({ }^{2} P\right)$ \\
\hline 29.24 & 95.08 & 1.03 & $2 s 2 p^{5}\left({ }^{1} P\right) 5 s\left({ }^{2} P\right)$ & 0.2 & 10 & 0.2 & $2 p^{4}\left({ }^{1} D\right)$ \\
\hline 29.68 & 51.24 & 0.72 & $2 p^{4}\left({ }^{3} P\right) 3 p\left({ }^{4} D\right) 4 p\left({ }^{3} ?\right)$ & & & 0.2 & $2 p^{5}\left({ }^{2} P\right)$ \\
\hline 29.80 & 95.64 & 0.66 & $2 s 2 p^{5}\left({ }^{1} P\right) 5 p\left({ }^{2} ?\right)$ & & 20 & & $2 p^{4}\left({ }^{1} D\right)$ \\
\hline 30.05 & 51.61 & 0.75 & $2 p^{4}\left({ }^{3} P\right) 3 p\left({ }^{2} S\right) 4 p(? P)$ & & & 0.4 & $2 p^{5}\left({ }^{2} P\right)$ \\
\hline 30.25 & 51.81 & 0.56 & $2 p^{4}\left({ }^{3} P\right) 3 p\left({ }^{4} D\right) 5 p\left({ }^{3} ?\right)$ & & & 0.3 & $2 p^{5}\left({ }^{2} P\right)$ \\
\hline $30.48^{b}$ & 52.04 & 1.02 & $2 p^{4}\left({ }^{3} P\right) 3 p\left({ }^{2} S\right) 5 p(? P)$ & 0.1 & 10 & 0.2 & $2 p^{5}\left({ }^{2} P\right)$ \\
\hline 30.81 & 96.65 & 0.62 & $2 s 2 p^{5}\left({ }^{1} P\right) 6 p\left({ }^{2} ?\right)$ & & 3 & 0.2 & $2 p^{4}(1 D)$ \\
\hline 31.07 & 52.63 & 0.95 & $2 p^{4}\left({ }^{1} S\right) 3 s\left({ }^{2} S\right) 3 p\left({ }^{1} P\right)$ & & 10 & 0.4 & $2 p^{5}\left({ }^{2} P\right)$ \\
\hline 31.20 & 97.04 & 0.96 & $2 s 2 p^{5}\left({ }^{1} P\right) 7 s\left({ }^{2} P\right)$ & 0.1 & & & $2 p^{4}(1 D)$ \\
\hline 31.82 & & & & & 8 & 0.5 & \\
\hline 32.15 & & & & & 0.5 & & \\
\hline 32.26 & & & & & & 0.05 & \\
\hline 32.62 & 54.18 & 0.16 & $2 p^{4}\left({ }^{1} S\right) 3 s\left({ }^{2} S\right) 3 d\left({ }^{?} D\right)$ & & & 0.3 & $2 p^{5}\left({ }^{2} P\right)$ \\
\hline 33.10 & & & & & & 0.5 & \\
\hline 33.37 & 54.93 & 0.18 & $2 p^{4}\left({ }^{1} S\right) 3 s\left({ }^{2} S\right) 4 d(? D)$ & & & 0.5 & $2 p^{\mathrm{5}}\left({ }^{2} P\right)$ \\
\hline 33.72 & 55.28 & 0.16 & $2 p^{4}\left({ }^{1} S\right) 3 s\left({ }^{2} S\right) 5 d\left({ }^{3} D\right)$ & & & 0.4 & $2 p^{5}\left({ }^{2} P\right)$ \\
\hline 34.57 & & & & & & 0.7 & \\
\hline 35.02 & & & & & & 0.8 & \\
\hline 35.22 & & & & & & 0.7 & \\
\hline 36.28 & & & & & & 0.5 & \\
\hline 38.27 & & & & & & 0.4 & \\
\hline
\end{tabular}

Quantum defects.

b This line could also be a transition from the $2 s 2 p^{5}\left({ }^{1} P\right) 6 s\left({ }^{2} P\right)$ excited state to the $2 p^{4}\left({ }^{1} D\right)$ final state in which case the initial-state energy would be 96.32 $\mathrm{eV}$ and the quantum defect 1.04 . 
TABLE II. Relative intensities of Auger transitions in neon.

\begin{tabular}{|c|c|c|c|c|}
\hline $\begin{array}{l}\text { Initial } \\
\text { state }\end{array}$ & Final state & $\begin{array}{l}\text { Rel. } \\
\text { intensity } \\
\text { proton } \\
\text { impact }\end{array}$ & $\begin{array}{c}\text { Rel. } \\
\text { intensity } \\
\text { electron } \\
\text { impact }^{\mathbf{2}}\end{array}$ & $\begin{array}{c}\text { Rel. } \\
\text { intensity } \\
\text { electron } \\
\text { impact }^{b}\end{array}$ \\
\hline$K\left({ }^{1} S\right)$ & $\begin{array}{r}\left.L_{2,3^{2}}{ }^{1} D\right) \\
\left({ }^{1} S\right) \\
L_{1} L_{2,3}\left({ }^{3} P\right) \\
\left.\quad{ }^{1} P\right) \\
L_{1}{ }^{2}\left({ }^{1} S\right)\end{array}$ & $\begin{array}{l}7.0 \pm 0.4 \\
1.5 \pm 0.2 \\
0.6 \pm 0.4 \\
2.5 \pm 0.4 \\
1.00\end{array}$ & $\begin{array}{c}13.1 \pm 0.6 \\
1.67 \pm 0.08 \\
0.98 \pm 0.05 \\
3.06 \pm 0.07 \\
1.00\end{array}$ & $\begin{array}{l}9.31 \\
1.55 \\
1.00 \\
2.73 \\
1.00\end{array}$ \\
\hline$K L_{2,3}\left({ }^{3} P\right)$ & $\begin{array}{r}L_{2,3^{3}}\left({ }^{2} D\right) \\
\left({ }^{2} P\right) \\
\left.L_{1} L_{2,3^{2}}{ }^{4} P\right) \\
\left({ }^{2} D\right) \\
\left({ }^{2} S\right) \\
\left({ }^{2} P\right) \\
L_{1}{ }^{2} L_{2,3}\left({ }^{2} P\right)\end{array}$ & $\begin{array}{c}1.9 \pm 0.3 \\
1.6 \pm 0.4 \\
\ldots \\
0.8 \pm 0.3 \\
\ldots \\
0.7 \pm 0.2 \\
1.1 \pm 0.2\end{array}$ & $\begin{array}{c}0.84 \pm 0.05 \\
0.41 \pm 0.04 \\
\ldots \\
0.19 \pm 0.04 \\
\ldots \\
0.16 \pm 0.04 \\
0.21 \pm 0.05\end{array}$ & \\
\hline$K L_{2,3}\left({ }^{1} P\right)$ & 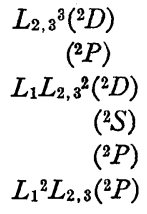 & $\begin{array}{c}0.8 \pm 0.2 \\
0.9 \pm 0.2^{\mathrm{c}} \\
0.2 \pm 0.2^{\mathrm{d}} \\
\ldots \\
0.5 \pm 0.2 \\
0.3 \pm 0.2\end{array}$ & $\begin{array}{c}0.50 \pm 0.04 \\
0.41 \pm 0.04 \\
\ldots \\
\ldots \\
0.22 \pm 0.04 \\
0.20 \pm 0.05\end{array}$ & \\
\hline$K L_{1}\left({ }^{3} S\right)$ & $\begin{array}{r}\left.L_{2,3^{3}}{ }^{2} P\right) \\
\left.L_{1} L_{2,3^{2}}{ }^{2} D\right) \\
\left({ }^{2} S\right) \\
L_{1}{ }^{2} L_{2,3}\left({ }^{2} P\right)\end{array}$ & $\begin{array}{c}\cdots \\
\cdots \\
0.7 \pm 0.3^{\mathrm{e}} \\
0.2 \pm 0.2^{\mathrm{d}}\end{array}$ & $\begin{array}{c}\cdots \\
0.16 \pm 0.05 \\
\cdots \\
\cdots\end{array}$ & \\
\hline$K L_{1}\left({ }^{1} S\right)$ & $\begin{array}{r}L_{2,3^{3}}\left({ }^{2} P\right) \\
L_{1} L_{2,3^{2}}\left({ }^{2} D\right) \\
\left({ }^{2} S\right) \\
L_{1}{ }^{2} L_{2,3}\left({ }^{2} P\right)\end{array}$ & $\begin{array}{c}\cdots \\
0.6 \pm 0.3 \\
\cdots \\
0.5 \pm 0.2\end{array}$ & $\begin{array}{l}\cdots \\
\cdots \\
\cdots \\
\cdots\end{array}$ & \\
\hline
\end{tabular}

See Ref. 4 .

b W. Mehlhorn, Z. Naturforsch. 23a, 287 (1968). These figures are from a recent redetermination of relative intensities in which a previous source of error has been eliminated.

c Lines not well resolved from stronger neighboring lines. d Lines not resol.
possible transitions.

One would expect to measure different cross sections for excitation of a given state by electrons and by protons. However, once that state is excited the relative probabilities of its decaying to various final states should be independent of the excitation method. This is found to be only approximately true on the basis of the
TABLE III. Relative cross sections for excitation of vacancy states in neon.

\begin{tabular}{lccc}
\hline \multicolumn{1}{c}{ State } & Proton impact & Electron impact & Electron impact ${ }^{\mathrm{b}}$ \\
\hline$K\left({ }^{1} S\right)$ & 12.6 & 19.81 & 15.59 \\
$K L_{2,3}\left({ }^{3} P\right)$ & 6.1 & 1.81 & \\
$K L_{2,8}\left({ }^{1} P\right)$ & 2.7 & 1.33 & \\
$K L_{1}\left({ }^{3} S\right)$ & 0.9 & 0.16 & \\
$K L_{1}\left({ }^{1} S\right)$ & 1.1 & $\cdots$ & \\
\hline \hline
\end{tabular}

S See Ref. 4

$b$ See footnote $b$ in Table II.

data available. Whether the departure from this expectation is due to experimental inaccuracy or to something more fundamental is not yet clear. It is obvious from the data that protons are much more effective than electrons in producing double vacancies in the energy range used in the two experiments (see Table III).

The major features of the Auger-electron spectrum from proton impacts were totally absent from the spectrum produced by $200-\mathrm{keV} \mathrm{Ne}^{+}$impacts. Instead, there appeared two very broad peaks at $750 \pm 10$ and $645 \pm 10 \mathrm{eV}$. The widths of these peaks were about 60 $\mathrm{eV}$ when measured with an analyzer resolution of 10 $\mathrm{eV}$. The lower-energy peak is the Doppler-shifited version of the former. These were first observed by Kessel, McCaughey, and Everhart, ${ }^{9}$ who interpreted them as being due to $K L L$ Auger transitions. However, since the largest of the $K L L$ peaks (the $804-\mathrm{eV}$ transition to a ${ }^{1} D$ final state) is missing in the $\mathrm{Ne}^{+}-\mathrm{Ne}$ work, we feel it is more likely that this is an unresolved group of many transitions from multivacancy states. The fact that two-, three-, and four-times ionized neon is seen in the products of such collisions ${ }^{9}$ lends support to this interpretation.

\section{ACKNOWLEDGMENT}

We wish to thank Dr. W. Mehlhorn for sending us his recent data prior to publication.

${ }^{9}$ Q. C. Kessel, M. P. McCaughey, and Edgar Everhart, Phys. Rev. Letters 16, 1189 (1966); Phys. Rev. 153, 57 (1967). 